\title{
Significance of the outer diameter of an endotracheal tube: a lesser-known parameter
}

\author{
Bhavna Gupta and Lalit Gupta \\ Department of Anesthesia, Maulana Azad Medical College and Lok Nayak Hospital, New Delhi, India
}

The diameter of catheters and tubings are typically measured by the French gauge system. Improper interpretation of these standards may lead to confusion between the users and catheter manufacturers. The outer diameter (OD) and inner diameter (ID) are generally measured in inches or millimeters.

The size of various tracheal tubes is usually expressed as ID, unless specified otherwise. Though the ID measurements may be constant, both OD and ID may show a difference of 2-4 $\mathrm{mm}$ depending on different manufacturers. For selecting an appropriate tracheal tube, the American society for testing and materials does not include any recommendations for OD measurement, as opposed to the recommendations available for ID measurements [1]. The OD and ID measurements of endotracheal tubes are summarized in Table 1.

Armored or flexo-metallic endotracheal tubes have a slightly thicker wall. The difference between OD and a standard ID is greater in an armored tube as compared to a regular endotracheal tube $(0.2-0.3 \mathrm{~mm})$. The size of a double lumen tube is decided by the size of the bronchus; this corresponds to the external diameter equivalent of a French catheter gauge, defined as 3 times that of the ID, hence the OD here is more important. The difference in the ODs of Univent and double lumen tubes as compared to that of a regular endotracheal tube is $2-3 \mathrm{~mm}$.

Corresponding author: Bhavna Gupta, M.B.B.S, D.A, D.N.B, MNAMS Department of Anesthesia, Maulana Azad Medical College and Lok Nayak Hospital, Bahadur Shah Zafar Marg, Balmiki Basti, New Delhi, Delhi 110002, India

Tel: 91-8527686660, Fax: 91-1126853108

Email: bhavna.kakkar@gmail.com

ORCID: https://orcid.org/0000-0002-3108-0408

Received: February 28, 2018.

Revised: March 13, 2018.

Accepted: May 8, 2018.

Korean J Anesthesiol 2019 February 72(1): 72-73

https://doi.org/10.4097/kja.d.18.00056
In a study published by Al-Mazrou et al. [2], the internal tracheal diameter (ITD) was measured at the level of the cricoid, using magnetic resonance images, and compared to the OD of a utilized endotracheal tube (ETT). The OD of the best fit ETT was less than the ITD measured at the level of the cricoid by 0.1-1.7 $\mathrm{mm}$, and it was concluded that the correlation of OD of the best fit ETT was strongerirrespective of weight or height. In another study by Bernet et al. [3], it was observed that the external diameter of pediatric tracheal tube cuffs could easily expand in vitro, to produce ODs of more than twice the age-corresponding ITD, when over-inflated with air.

It has been observed that if the ID is too small, it may result in a smaller OD, which increases the cuff pressure required to create a seal in the trachea. A smaller ID tube also increases the

Table 1. Recommended ID and OD of Endotracheal Tubes

\begin{tabular}{|c|c|c|c|}
\hline Age & Weight & $\begin{array}{l}\text { Endotracheal } \\
\text { tube diameter } \\
\text { (ID) }(\mathrm{mm})\end{array}$ & $\begin{array}{c}\text { Endotracheal } \\
\text { tube diameter } \\
(\mathrm{OD})(\mathrm{mm})\end{array}$ \\
\hline \multirow[t]{2}{*}{ Neonates } & $0.7-1.5 \mathrm{~kg}$ & 2.5 & 3.4 \\
\hline & $1.6-3.2 \mathrm{~kg}$ & 3 & 4.2 \\
\hline \multirow[t]{3}{*}{ Infants } & $0-3$ months & 3.5 & 4.8 \\
\hline & $3-6$ months & 4 & 5.4 \\
\hline & 6-12 months & 4.5 & 6.2 \\
\hline \multirow[t]{7}{*}{ Children } & $2-3 \mathrm{yr}$ & 5 & 6.8 \\
\hline & $4-5 \mathrm{yr}$ & 5.5 & 7.4 \\
\hline & $6-7 \mathrm{yr}$ & 6 & 8.2 \\
\hline & $8-9$ yr & 6.5 & 8.8 \\
\hline & $10-11 \mathrm{yr}$ & 7 & 9.6 \\
\hline & $12-13 \mathrm{yr}$ & 7.5 & 10.2 \\
\hline & $14-15 \mathrm{yr}$ & 8 & 11 \\
\hline \multirow[t]{5}{*}{ Adults } & Female & 7.5 & 10.2 \\
\hline & & 8 & 11 \\
\hline & Male & 8.5 & 11.6 \\
\hline & & 9 & 12.2 \\
\hline & & 9.5 & 13 \\
\hline
\end{tabular}

ID: inner diameter, OD: outer diameter.

(c) This is an open-access article distributed under the terms of the Creative Commons Attribution Non-Commercial License (http://creativecommons.org/ licenses/by-nc/4.0/), which permits unrestricted non-commercial use, distribution, and reproduction in any medium, provided the original work is properly cited. 
resistance through the tube, making the airway clearance more difficult. However, a tube with a larger OD would be more difficult to pass through a stoma.

The OD may be implicated in post extubation edema, sore throat, sub-glottis inflammation, long term stenosis, and other complications; however, research studies may be required to record this observation. The OD is also important to allow smooth passage of ETT through the supra-glottic airway devices. Additionally, attention should be paid to the OD when using an endotracheal tube of different material such as polyvinylchloride (PVC) or silicon, although the most commonly used ones are made up of PVC. Further, it becomes imperative to check the compatibility between the supra-glottic device and endotracheal tube in emergency intubation of the trachea. The OD of a tracheostomy tube should be about $2 / 3-3 / 4$ of the tra- cheal diameter. A tube should not be wider than $10 \mathrm{~mm}$ in adult females and $11 \mathrm{~mm}$ in adult males, to minimize the trauma to the tracheal wall and avoid long term complications [4]. The ID influences the physiology of breathing and course of weaning off from the ventilator.

In conclusion, one must ascertain both the ID as well as the OD of tracheal tubes and accordingly decide the size of tube especially in long lasting surgeries and in cases presenting higher chances of post-operative vocal cord edema.

\section{ORCID}

Bhavna Gupta, https://orcid.org/0000-0002-3108-0408

Lalit Gupta, https://orcid.org/0000-0001-7291-5961

\section{References}

1. Dullenkopf A, Kretschmar O, Knirsch W, Tomaske M, Hug M, Stutz K, et al. Comparison of tracheal tube cuff diameters with internal transverse diameters of the trachea in children. Acta Anaesthesiol Scand 2006; 50: 201-5.

2. Al-Mazrou KA, Abdullah KM, Ansari RA, Abdelmeguid ME, Turkistani A. Comparison of the outer diameter of the 'best-fit' endotracheal tube with MRI-measured airway diameter at the cricoid level. Eur J Anaesthesiol 2009; 26: 736-9.

3. Bernet V, Dullenkopf A, Maino P, Weiss M. Outer diameter and shape of paediatric tracheal tube cuffs at higher inflation pressures. Anaesthesia 2005; 60: 1123-8.

4. Bodenham A, Bell D, Bonner S, Branch F, Dawson D, Morgan P, et al. Standards for the Care of Adult Patients with Temporary Tracheostomy; Standards and Guidelines [Internet]. Intensive Care Society Standards; 2014 [cited 2018 Aug 16]. Available from https:// www.theawsomecourse.co.uk/ICS/ICS\%20Tracheostomy\%20standards\%20(2014).pdf 